\title{
A Multi-Systems Approach to Human Movement after ACL Reconstruction: The Cardiopulmonary System
}

\author{
Lucas Seehafer, PT, DPT, OCS ${ }^{1}$, Scot Morrison, PT, DPT, OCS, CSCS ${ }^{2}$, Rich Severin, PT, DPT, PhD(c), CCS ${ }^{3}$ Brandon M \\ Ness, PT, DPT, PhD, $\mathrm{SCS}^{4}$ a \\ 1 Optivus Physical Therapy, ${ }^{2}$ PhysioPraxis PLLC; Department of Neuroscience, Biomedicine and Movement Sciences, University of Verona, ${ }^{3}$ Doctor of \\ Physical Therapy Program, Baylor University; Department of Physical Therapy, College of Applied Health Sciences, University of Illinois, 4 Doctor of \\ Physical Therapy Program, Tufts University School of Medicine \\ Keywords: anterior cruciate ligament, anterior cruciate ligament reconstruction, cardiopulmonary, movement system, rehabilitation \\ https://doi.org/10.26603/001c.29451
}

International Journal of Sports Physical Therapy

Vol. 17, Issue 1, 2022

The cardiopulmonary system plays a pivotal role in athletic and rehabilitative activities following anterior cruciate ligament reconstruction, along with serving as an important support for the functioning of other physiologic systems including the integumentary, musculoskeletal, and nervous systems. Many competitive sports impose high demands upon the cardiorespiratory system, which requires careful attention and planning from rehabilitation specialists to ensure athletes are adequately prepared to return to sport. Cardiopulmonary function following anterior cruciate ligament reconstruction (ACLR) can be assessed using a variety of methods, depending on stage of healing, training of the clinician, and equipment availability. Reductions in cardiovascular function may influence the selection and dosage of interventions that are not only aimed to address cardiopulmonary impairments, but also deficits experienced in other systems that ultimately work together to achieve goal-directed movement. The purpose of this clinical commentary is to present cardiopulmonary system considerations within a multi-physiologic systems approach to human movement after ACLR, including a clinically relevant review of the cardiopulmonary system, assessment strategies, and modes of cardiopulmonary training to promote effective, efficient movement.

\section{Level of Evidence}

5

\section{INTRODUCTION}

Systems with multiple levels cannot be fully understood by examining their component parts, as the outcome of their interactions is different from the sum of the parts. Since 2013, the American Physical Therapy Association (APTA) has promoted the movement system in physical therapist practice, education, and research as 'the foundation for optimizing movement to improve the health of society." Through the integration of body systems and functions, the movement system essentially refers to the body's ability to produce and sustain movement. ${ }^{2}$ Barriers to implementation and validation have arisen since the adoption of the term movement system with efforts ongoing to promote its use. ${ }^{3,4}$ A framework that has been more readily accepted for describing motor control, movement dysfunction, and skill acquisition is a dynamical systems theory approach. ${ }^{5}$ Dynamical systems theory aims to explain variability in goaldirected human movement and enhance the understanding of a complex system through its component parts. ${ }^{5}$ Similarly, the APTA movement system and dynamical systems theory place importance upon the functions and interactions of component systems in support of the entire system as a whole. A physiologic system, individually, can be representative of a component system that is needed for achieving purposeful, goal-oriented human movement. With this understanding, a multi-physiologic systems approach may offer a useful perspective for clinicians during rehabilita-

\footnotetext{
a Correspondence:

Brandon Ness, PT, DPT, PhD

Doctor of Physical Therapy Program

Tufts University School of Medicine

136 Harrison Ave

Boston, MA, 02111

Email:Brandon.Ness@tufts.edu
} 
tion after anterior cruciate ligament reconstruction (ACLR). The purpose of this clinical commentary is to present cardiopulmonary system considerations within a multi-physiologic systems approach to human movement after ACLR, including a clinically relevant review of the cardiopulmonary system, assessment strategies, and modes of cardiopulmonary training to promote effective, efficient movement.

\section{CARDIOPULMONARY SYSTEM CONSIDERATIONS AFTER ANTERIOR CRUCIATE LIGAMENT RECONSTRUCTION (ACLR)}

The cardiopulmonary system has important roles when interacting with other systems such as thermoregulation when performing cardiovascular training, ${ }^{6}$ providing blood flow to working muscles during strength training, ${ }^{7}$ and supporting a highly metabolically active nervous system. This is not to mention the association between aerobic activity and improved cognition in older populations ${ }^{8}$ and enhanced executive function in younger individuals (ages 20-67). ${ }^{9}$ The cardiopulmonary system, along with other body systems, experiences change after ACLR. Anterior cruciate ligament (ACL) injuries typically occur while landing from a jump or with change of direction, which is common in several team sports such as basketball, soccer, and football. ${ }^{10}$ These sports require high-intensity intermittent actions interspersed with sustained low-intensity activities. Since most of these sports are predominantly running based these efforts fall under "repeated-sprint ability" (RSA) which is defined as brief sprints $(<10 \mathrm{~s})$ followed by incomplete $(<60 \mathrm{~s})$ recovery. ${ }^{11,12}$ These activity requirements place unique demands on both the anaerobic and aerobic energy systems. ${ }^{13,14}$ Ultimately all three energy systems (phosphocreatine, glycolytic, aerobic) will be involved during intermittent cycles of sprint-recovery, but the degree to which each energy system is utilized depends on factors including but not limited to the particular sport, the position(s) played, and game/match situation or phase.

For example, a recent systematic review examining the activity demands during basketball reported guards performed more high-intensity movements throughout the course of a basketball game compared to forwards and centers. ${ }^{15}$ Although the demands for each sport and individual may be unique, the general energy system demands seen across field and court sports (which also tend to be where most ACL injuries occur) are broadly similar. ${ }^{16}$ After an ACL injury, these energy systems become detrained secondary to the reduction in stimulus in accordance with the specific adaptation to imposed demands (SAID) principle. This shift in ability can be viewed as the envelope moving "to the left" if viewed within the "envelope of function" model. ${ }^{17}$ This model, initially proposed by Scott Dye for the musculoskeletal system, contrasts the individual's physiological capacity with the task demands on an intensity/duration spectrum and has been adapted for this commentary to apply to the cardiopulmonary system, as depicted in Figure 1. The goal of rehabilitation is to shift the envelope of function to the right so that the task demands fall below the maximum tolerated line. Unfortunately, rehabilitation of-

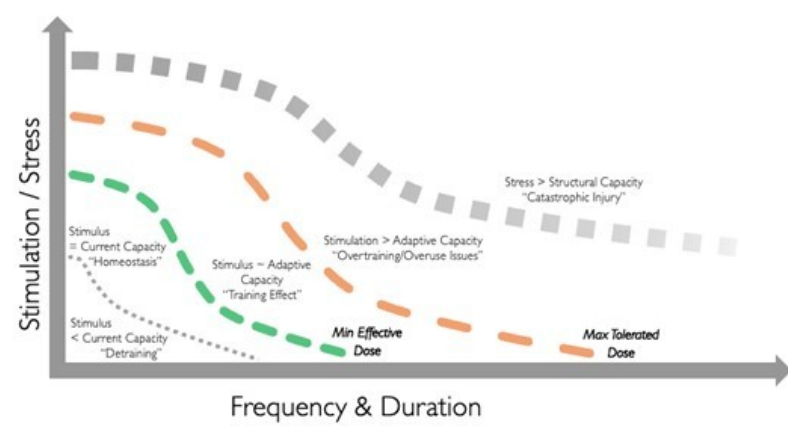

Figure 1. Physiological Response to Task Demands

Used with permission from PhysioPraxis PLLC. Cited in Morrison S, Sloptima Loading:ExRx for Rehabilitation Professionals Course Manual, 2020.

ten fails to fully address this shift, resulting in athletes returning to play without the energy system development needed for their sport. ${ }^{18}$

Since clinical tests of the cardiopulmonary system predominantly measure change in performance as a proxy for cardiopulmonary system changes, it is important to understand that performance can improve due to a combination of underlying factors and may not reflect the adaptations desired. For example, cardiac output is the product of heart rate (HR) and stroke volume (SV) which is further determined by ventricular volume and ejection fraction. An increase in performance after an intervention to address central factors such as SV could be seen due to an increase in HR alone which would indicate a failed intervention but still show an increase in performance. As such, the clinician must interpret test results with caution and rely on sound exercise prescription principles that maximize the probability of seeing the desired adaptations being addressed. The impacts of undergoing ACLR on the cardiopulmonary system are under-represented in the scientific literature compared to other areas of the rehabilitation and recovery process. Most of the available literature addressing detraining of the cardiopulmonary system focuses on issues secondary to cessation of activity in an uninjured population. In turn, much of the available literature on detraining and re-training post-ACLR focuses on neuromusculoskeletal impairments and return to sport. ${ }^{19}$

\section{CARDIOPULMONARY SYSTEM REVIEW}

Competitive athletics impose high demand upon the cardiorespiratory system. For example, during a 90-minute soccer game, players have been reported to run $\sim 10 \mathrm{~km}$ at intensities as high as $75 \%$ of their peak oxygen uptake (VO2 peak) as well as covering $215+/-100$ meters at sprint speeds. ${ }^{13,20,21}$ Significant demands on the cardiopulmonary system ${ }^{22}$ are seen across a wide variety of sports including those viewed as anaerobic such as American football $^{23}$ which requires wide receivers to cover 5,530.6 +/685.6 yards in a game that includes $22+/-8$ max acceleration efforts. ${ }^{13,21}$ Human physiology relies on the energy stored in one of the phosphate bonds in adenosine triphosphate (ATP) to power all activities. Breaking this bond 
Table 1. Sport Specific Demands ${ }^{22-26}$

\begin{tabular}{|c|c|c|c|c|}
\hline Sport & $\begin{array}{l}\text { Work:Rest } \\
\text { Ratio }\end{array}$ & $\begin{array}{l}\text { Total Locomotor } \\
\text { Distance } \\
\text { (mean } \pm \text { SD) }\end{array}$ & Intensity & Movement Demands \\
\hline Basketball & $6 \mathrm{sec}: 22 \mathrm{sec}$ & $7,558 \pm 575$ meters & $\begin{array}{l}\text { Sprint Efforts }=55 \pm 11 \\
\text { COD/Lateral Movement }= \\
94 \pm 16 \\
\text { Jumps }=44 \pm 7\end{array}$ & $\begin{array}{l}\text { - COD } \\
\text { - Lateral movement } \\
\text { - Jumping } \\
\text { - Acceleration/ } \\
\text { Deceleration }\end{array}$ \\
\hline $\begin{array}{l}\text { American Football } \\
\text { (WR) }\end{array}$ & $5.23 \mathrm{sec}: 36 \mathrm{sec}$ & $\begin{array}{l}5,530.6 \pm 685.6 \\
\text { yards }\end{array}$ & $\begin{array}{l}\text { Sprints }=13 \pm 6 \\
\text { Max Accel Efforts }=22 \pm 8 \\
\text { Max Decel Efforts }=16 \pm 5\end{array}$ & $\begin{array}{l}\text { - Sprint } \\
\text { - Acceleration/ } \\
\text { Deceleration } \\
\text { - Collision/Contact }\end{array}$ \\
\hline Soccer & $\begin{array}{l}8.5: 4.4 \\
\text { purposeful } \\
\text { movements }\end{array}$ & $\begin{array}{l}11,393 \pm 1,016 \\
\text { meters }\end{array}$ & $\begin{array}{l}\text { Sprint Distance }=215 \pm 100 \\
\text { meters }\end{array}$ & $\begin{array}{l}\text { - Sprint } \\
\text { - Acceleration/ } \\
\text { Deceleration } \\
\text { - COD }\end{array}$ \\
\hline
\end{tabular}

$\mathrm{COD}=$ change of direction

Used with permission from Patrick Ward, from “Building a Better Athlete” presented at the American Academy of Sports Physical Therapy’s Annual Meeting and Scientific Conference 2021.

changes ATP to adenosine diphosphate (ADP) which must then be converted back to ATP by one of the three main energy systems: phosphocreatine (ATP-Pcr), glycolytic, and aerobic. ${ }^{18}$ The cardiopulmonary system plays a key role in supplying the required energy resources and shuttling off by-products such as carbon dioxide, lactate and $\mathrm{H}+$ ions. The following section briefly outlines some of the key considerations for the various energy systems.

\section{PHOSPHOCREATINE (ATP-PCR) SYSTEM}

An important component of the ATP-Pcr system, creatinephosphate (CP), assists with anaerobic production of ATP for quick bursts of activity and muscle contractions in response to the demands of the sport as outlined in Table 1. ${ }^{22-26}$ These CP levels fall significantly during brief intense activity, such as during high-speed efforts in soccer where they can drop below $75 \%$ of resting levels due to the energetic demands. ${ }^{27,28}$ In fact, it has been estimated that the actual drop in CP may be closer to $60 \%$ of the resting levels. $^{27,28}$ It has been reported that CP levels in individual muscle fibers experience near depletion when fatigue occurs as a result of repeated intense activities showcasing the importance of the energy system's ability to rapidly replenish. ${ }^{27,29}$ This system is limited by the storage of ATP and phosphocreatine, relies on the aerobic system for recovery, and is limited in trainability. ${ }^{18,30}$ Due to its nature and the limited adaptative potential of this system it tends to both train and detrain rather quickly ( $<2-3$ weeks) which means that it is best trained and maintained via brief and frequent exposures when needed to supplement practice and game demands. ${ }^{18}$

\section{GLYCOLYTIC SYSTEM}

Lactate is a key byproduct of the glycolytic system due to cellular metabolism in muscles working to meet the demands of exercise. ${ }^{31,32}$ This process occurs when pyruvate production exceeds the uptake ability of the glycolytic mus- cle fiber resulting in its reduction to lactate. ${ }^{31,32}$ This molecule has had an interesting history and was viewed as a waste product and cause of fatigue for most of the 20th century. The reality is that it acts a buffer against fatigue due to its use of $70-75 \%$ of the released $\mathrm{H}+$ ions for transportation out of the working muscle and becomes an important energy source during high intensity exercise when it is aerobically metabolized by an oxidative muscle fiber. ${ }^{31}$ It can also be used by the heart, liver, or brain as an energy source and functions as a pseudo-hormone where it interacts as a signaling molecule with multiple anabolic pathways and plays a role in norepinephrine release and brain plasticity. ${ }^{31}$ Multiple studies have described the average blood lactate threshold ([BLa]) among athletes during soccer games to be 2-10 mmol with muscle lactate concentrations ([MLa]) increasing to approximately $4 \mathrm{mmol} / \mathrm{kg}$ after periods of intense activity, which is an increase of $400 \%$ from resting values. ${ }^{28,33-37}$ Lactate can be converted to pyruvate and subsequently glucose through the process of gluconeogenesis where it functions as a fuel source for the aerobic system.

Glycogen is a "readily mobilized storage form of glucose" which is an important energy source during prolonged athletic activity. ${ }^{38}$ Studies have reported inconsistent levels to which glycogen is reduced during the course of a soccer game, with some noting decreases of $90 \%$ (from $100 \mathrm{mmol} /$ $\mathrm{kg}$ to $10 \mathrm{mmol} / \mathrm{kg}$ ) while others report decreases of only $35-60 \%$ (from $100 \mathrm{mmol} / \mathrm{kg}$ to $40-65 \mathrm{mmol} / \mathrm{kg}$ ). ${ }^{27}$ Much like with CP levels, muscle glycogen levels have been found to decrease dramatically in individual muscle fibers in direct relation to the duration of activity over the anaerobic threshold regardless of muscle fiber type. ${ }^{27,28}$ The glycolytic energy system is fairly trainable but produces energy at a slower rate (50\% of AT-Pcr) and also adapts at a faster rate compared to the aerobic system ( $3-4$ weeks). ${ }^{18}$ 


\section{AEROBIC SYSTEM}

The aerobic system produces ATP at the lowest rate per unit time but is limited by oxygen supply and uptake as well as the availability of various substrates and enzymes. It also plays a significant role in recovery between intense bouts and contributes a significant portion of the ATP used during repeated sprints. ${ }^{39}$ This system is highly trainable due to its high ceiling for adaptation but also takes much longer to train (four to eight weeks for initial changes and three to four months for significant adaptations) compared to the previous two systems. ${ }^{18,30,40}$ After cessation of training, the athlete's aerobic performance can be maintained for $\sim 1$ month with increases in HR at similar intensities compensating for early detraining effects such as blood volume changes and loss of ventricular size. ${ }^{18,30,40}$ As detraining continues, all adaptations will reverse at a rate similar to the initial adaptation and by 3-4 months the majority of previous adaptations will have been lost. $18,30,40$

Of primary concern following ACLR is the effect of detraining "partial or complete loss of training-induced anatomical, physiological and performance adaptations"40(p80) on cardiovascular fitness. Reductions in cardiovascular function may influence the selection and dosage of interventions that are not only aimed to address cardiopulmonary impairments, but deficits experienced in other systems as well. In an athlete who has undergone ACLR, long term ( $>4$ weeks) changes in cardiovascular fitness are generally the most relevant. Studies on detraining show a longer term drop of maximum rate of oxygen consumption (VO2max) in highly trained individuals of up to $20 \%$ after cessation of exercise. ${ }^{41,42}$ In trained individuals, this decrease in VO2max was much more significant with some studies showing a complete regression to untrained levels in a similar timeframe after cessation of exercise. ${ }^{40}$ When examined in a ACLR population, VO2max was 20\% lower pre- and $15 \%$ lower six months post-ACLR in professional soccer athletes when compared to controls. ${ }^{13}$ However, while VO2max is a metric that is often used it suffers from lack of ability to predict performance, especially in RSA type settings, and changes in VO2max do not always accurately reflect underlying adaptations to training and detraining. ${ }^{42,43}$ In the same study on soccer players, athletes post ACLR had significantly slower running speeds compared to controls pre- and six months post-ACLR at both anaerobic threshold (VTI), which is the point at which lactate begins to accumulate within the blood and ventilation rate increases in an attempt to clear the increased production of carbon dioxide (CO2), and lactate threshold (VT2) which occurs when the buffer system is no longer able to clear lactate at the rate it is produced. ${ }^{13}$

The acute deconditioning following an ACL injury results in a reduction in peak VO2 (VO2peak) due to changes occurring both in the peripheral muscle and due to myocardial remodeling. ${ }^{44}$ Even after completing a full ACLR rehabilitation program many athletes may still demonstrate reduced VO2peak and ventilatory threshold (VT). ${ }^{13,44}$ This reduction in aerobic conditioning is of concern, as certain field tests have been shown to be valid assessments of estimating aerobic endurance performance ${ }^{45}$ while also holding predictive value for lower extremity musculoskeletal injuries. ${ }^{46}$
Attaining adequate sport-specific fitness levels may be important to better prepare for the demands of the sporting tasks. Participating in a preseason seven-week conditioning program that included cardiovascular conditioning was associated with reduced lower extremity injury rates compared to those who were untrained, and should be included as part of a comprehensive conditioning program. ${ }^{47}$ By adequately training cardiopulmonary fitness, this may have an impact on musculoskeletal health and should be considered when taking a multi-physiologic systems approach to rehabilitation after ACLR.

\section{RESULTS OF DETRAINING}

\section{CARDIOVASCULAR}

Complete cessation of exercise training (detraining) results in a multitude of physiological changes in the cardiovascular system which are initiated primarily by reductions in circulating plasma volume. ${ }^{48}$ Significant reductions in plasma volumes have generally been reported following four weeks of detraining but may occur after only two days. ${ }^{49}$ This reduction in circulating plasma volume reduces cardiac preload which induces a concomitant remodeling to the heart. ${ }^{48}$ This cardiac remodeling appears to follow a structure-specific pattern. Pedlar et al reported that four weeks of detraining caused significant reductions in left ventricular (LV) wall thickness, LV mass, and right atrial area. ${ }^{48}$ However, after eight weeks of detraining a significant reduction in right ventricle chamber size was observed but without any additional changes to the LV wall thickness. ${ }^{48}$ Along with these structural changes to the heart, many functional changes occur. Following two to four weeks of detraining, a $12 \%$ reduction in exercise SV, and an $11 \%$ increase in submaximal HR have been reported. ${ }^{50}$ These changes to HR responses following detraining have been attributed to multiple mechanisms including reduced parasympathetic outflow to the sinoatrial node, altered baroreceptor sensitivity, and beta-adrenergic hypersensitivity. ${ }^{51}$ Additionally, total heart volume (THV) and ventricular end diastolic volume decreases following ACLR, however, it appears as though only THV spontaneously improves upon reinitiating exercise training. 13,44,52,53 Additionally, reductions in end diastolic volume, SV, cardiac output (CO), ejection fraction, hemoglobin concentration, and hematocrit and increase resting heart rate have been observed in soccer players after ACLR. ${ }^{54}$ Altogether these physiological adaptations to the heart following detraining impair CO and reduce peak exercise capacity, which in turn may impact other interventions that target other body systems that ultimately work together to create efficient, goaldirected movement.

In addition to changes in the heart, detraining may augment circulatory and ventilatory responses to exercise. After two to four weeks of detraining has been shown increase total peripheral resistance, ${ }^{50}$ reduce skeletal muscle capillarization, ${ }^{55}$ and reduce conduit artery diameter and blood flow. ${ }^{56}$ These vascular changes impair perfusion and oxygen delivery to working muscles and also increase cardiac afterload. 50 The changes in blood flow to working muscles may be an important physiologic system integration especially 
after ACLR, as recovery of quadriceps strength is a key facet of rehabilitation and impacts patient outcomes. 57,58

\section{PULMONARY/VENTILATORY}

The effects of detraining on ventilatory responses are inconsistent in the literature. Attenuated initial ventilatory responses have been reported following 20 days of inactivity. ${ }^{59}$ Detraining has also been shown to reduce maximal ventilatory volume and oxygen pulse during exercise. ${ }^{40}$ However, these effects on the respiratory system appear to be more pronounced in highly trained athletes. ${ }^{40}$ No significant changes in ventilatory responses or markers of ventilatory efficiency (VE/VCO2 slope) were found following six weeks of detraining in young soccer players. ${ }^{60}$

\section{CARDIOPULMONARY SYSTEM ASSESSMENT AFTER ACL RECONSTRUCTION}

Cardiopulmonary function following ACLR can be assessed using a variety of methods, depending on stage of healing, training of the clinician, and equipment availability. It is important to consider what is being measured when a test is chosen. Broadly speaking, the workload and the individual's response can be divided into external (the workload imposed on the organism), internal (the physiological response to the external workload), and psychophysiological (the perception of effort by the individual). ${ }^{61}$ Heart rate is one of the most common methods used to evaluate and predict overall cardiorespiratory fitness for team-based athletics; however, other assessments have been utilized including blood lactate concentration ([BLa]), estimated VO2max, rating of perceived exertion (RPE), metabolic equivalent testing (MET), respiratory exchange ratio (RER), and VT. 13,14,62 A method for determining overall fitness that has become more accessible due to advances in technology is energy expenditure (EE). ${ }^{63,64} \mathrm{EE}$ is a useful metric as it can be expressed as the amount of energy an individual expends across several conditions, which may include rest, submaximal/maximal exercise, or recovery after exercise. ${ }^{65}$ EE can be assessed in a variety of ways including wearable options like accelerometry, pedometry, and more intensive options such as indirect calorimetry (IC) or the doubly-labeled water (DLW) method. ${ }^{64}$

\section{HEART RATE}

HR assessment is a measure of internal workload and has many options of implementation such as a manual or automated measure of pulse rate, electrocardiogram (ECG), and Holter machine monitoring. These methods have been utilized since at least the 1970's to quickly assess HR with varying degrees of accuracy. ${ }^{66,67}$ However, starting in the 1980's, access to HR monitoring via ECG chest straps and wrist-worn electronic devices have been the preferred option. HR monitoring with chest-worn ECGs as well as wristworn optical blood flow monitors have provided accurate HR readings when compared to ECG, though it is believed that chest-worn devices provide greater accuracy. $66,68-70$ As with any measurement, the proper use of the device is key for determining an accurate HR regardless of the model.
Speed is another factor that can influence readings with some data showing the accuracy of HR monitoring devices may decrease with increased speed, particularly when running. ${ }^{67-70}$ While there is a large amount of data on HR in team sport athletes at various levels of play, most of this research has been conducted on male subjects.

\section{RATING OF PERCEIVED EXERTION (RPE)}

The use of RPE is based on the subject's perception of effort to the external load and is therefore a measure of psychophysiological load. However, it has been shown to correlate well with other measures such as HR and blood lactate levels. ${ }^{71}$ Gunnar Borg developed the Borg Scale in 1982 to quantify perceived exertion during activity and modeled it on measures of heart rate. ${ }^{72}$ In the Borg Scale, the participant typically rates their perceived level of exertion on a scale of 6 to 20, with higher numbers representing a greater effort. A modified version of the Borg Scale (CR-10) has also been developed with perceived exertion rated on a 1 to 10 scale. ${ }^{73,74}$ The Borg Scale is highly correlated with HR as well as [BLa] and has been found to be a valid method for estimating session workloads. ${ }^{71}$ While both the original or modified Borg Scale can be utilized at various stages throughout the course of rehabilitation following ACLR, the modified scale tends to be easier to implement. This is especially true if using session RPE which gives a rating of total session workload (sRPE). The sRPE is calculated by taking the total duration of the session and multiplying it by the RPE obtained after the session ends. In general, it is advised that the SRPE be taken a short period after the session has ended but there is no need to wait the original $30 \mathrm{~min}$ utes. ${ }^{18}$ For reliability, it is important to use both the verbal and visual anchors and perform the collection the same way every time.

\section{CARDIOPULMONARY EXERCISE TESTING (CPET)}

While various field tests can provide an assessment of aerobic fitness which may estimate VO2peak, the most accurate method is the use of Cardiopulmonary Exercise Testing (CPET) with analysis of expired ventilatory gases. ${ }^{75,76}$ Guidelines on standardized testing parameters have been provided by various professional organizations. ${ }^{76}$ Most protocols utilize either a stationary cycle ergometer or treadmill. ${ }^{76}$ There have also been protocols adopted using motor driven skate treadmills for hockey players ${ }^{77}$ and treadmill skiing. Additional measures obtained from CPET such as VT are also indicators of training status and physical condition across sports. ${ }^{21,78}$ There is some data to suggest the implementation of CPET such as in pre-season where VO2peak was shown to be an independent predictor of injury at any point during the competitive season in collegiate soccer players. ${ }^{79}$

Despite the well-established relationship between the data obtained from CPET, notably VO2peak and VT, its use in return to sport decision making following ACLR is limited, likely due to equipment availability and time constraints. Most of the available literature investigating the role of CPET for return to sport following ACLR has been in soccer players. ${ }^{13}$ De Almeida et al reported that even after 
six months of rehabilitation following ACLR in professional soccer players both VO2peak and VT were still reduced compared to non-injured athletes. ${ }^{13}$ It is worth noting that VO2peak typically remains stable within season and between seasons in elite soccer players. ${ }^{80}$ Therefore, the differences in the study by De Almeida essentially reflects reductions compared to population-based norms. These results suggest that CPET can be used to accurately identify persistent impairments in VO2peak and other markers of aerobic fitness following ACLR. These measurements obtained by CPET can be compared to sport specific measures to accurately and objectively determine if an athlete has attained the requisite aerobic fitness for their sport. The use of preseason CPET may also permit athlete-specific comparisons following ACLR and assist in screening and injury risk reduction processes.

\section{MAXIMUM AEROBIC SPEED (MAS)}

Much like RPE, maximum aerobic speed (MAS) is one of the most clinically friendly ways to both assess an individual's fitness and obtain a metric that can be used for programming. This combined with the fact that it only takes five minutes makes it a very easily implemented option. This test is designed to give the maximum speed at which the task can be performed while relying on the aerobic system. ${ }^{18,81,82}$ The test can be performed on any piece of equipment that allows for a measurement of total work done but traditionally is used with running, biking, or rowing. To perform the test, the individual is encouraged to go as far/hard as they can for a 5-minute period after which the total distance is divided by time. For a detailed review of prescription in rehabilitation based on MAS see Morrison et al. ${ }^{18}$

\section{WINGATE TEST}

The Wingate Test is one of the most frequently utilized tools for assessing anaerobic conditioning and muscle power production. The test involves cycling with 100\% effort on a stationary bike ergometer for 30 seconds with a resistance, sometimes referred to as breaking force, of $7.5-8.9 \%$ of the participant's body mass, though some authors advocate for the resistance to be as high as $11 \% 83,84$ The Wingate Test has been researched significantly and has been determined to be a reliable assessment. ${ }^{84,85}$ Normative values have been established for men's soccer ${ }^{86}$ and highly-trained women participating in various sports. ${ }^{87}$

While the Wingate Test primarily assesses anaerobic performance, it has been estimated $18-30 \%$ of the participant's performance can be tied to their aerobic conditioning. ${ }^{84} \mathrm{Be}-$ cause the Wingate Test does not require a change in motion and is largely non-weight-bearing, it can be conducted earlier in rehabilitation compared to other tests that place higher demands on the musculoskeletal system. It can be completed once the athlete has obtained sufficient quadriceps control and has been cleared to exercise on a stationary bike. Specific timeframes will vary, but it is feasible the Wingate Test may be implemented as early as one to three months post-ACLR depending on surgical and patient factors.

\section{YO-YO INTERMITTENT RECOVERY TEST}

The Yo-Yo intermittent recovery test comes in three different variations and assesses both aerobic and aerobic conditioning. It involves the participant running from one marker to another placed 20-m away and then back to the first followed by a 10 second recovery interval where they walk/jog to a third cone five meters back from the starting cone. This test progressively increases the velocity in stages until the subject fails to arrive at the designated cone in the allotted time for the second time. ${ }^{13,88}$ The participant's speed is dictated by electronic beeps that sound more rapidly as the test progresses. The full Yo-Yo intermittent recovery test can be completed on two levels, with level one having a starting speed of $10-13 \mathrm{kph}$ and level two starting at $13-15 \mathrm{kph}$. There is also a rehabilitation specific variation that has been proposed using time as a cutoff and tracking $\mathrm{HR}$ at that point. The assessment has been found to have high reproducibility, sensitivity, and is a valid aerobic conditioning test for male athletes, however, it's validity among female athletes has been questioned. ${ }^{88,89}$ Reference values have been established for males and females across multiple sports and various levels of play. ${ }^{88}$

The Yo-Yo intermittent recovery test requires running at fast speed as well as multiple changes of direction. Therefore, the rehabilitation specialist should be confident that the athlete has reached the appropriate rehabilitation milestones prior to administering the assessment. It is the perspective of the authors that the Yo-Yo intermittent recovery test is usually conducted beginning six months following ACLR depending on clinical status.

\section{MODES OF CARDIOPULMONARY SYSTEM TRAINING}

The mode and progression of cardiopulmonary training is typically determined by several factors such as postoperative timeframe, clinical status, and training goal(s). The reader is referred to Buckthorpe et al $2020^{90}$ for a ten taskbased progression following ACLR. The tasks in the progression include walking, bilateral foundational movements, unilateral foundational movements, bilateral landing, running, bilateral plyometrics, unilateral jumping/landing, unilateral plyometrics, pre-planned multidirectional movements, and sport-specific movements. Although many options for cardiopulmonary training exist, several common applications for post-ACLR will be discussed.

The primary focus of cardiopulmonary training during the first few months after ACLR is to maintain and (re)develop a baseline level of aerobic conditioning as the surgical graft heals and impairments in other physiologic systems (musculoskeletal, integumentary, nervous) are addressed. For example, interventions that target the musculoskeletal system typically aim to address deficits in range of motion and strength during the early postoperative timeframe, which impacts the mode and dosage options available for cardiopulmonary training. Many modes of exercise exist that address aerobic deconditioning while subjecting the healing ACL to minimal amounts of force. More traditional activities such as some aquatic exercise (considerations for 
graft strain with kicking motion are discussed below), upper extremity ergometry, cycling, or elliptical running may be viable options. ${ }^{91}$ Additional modalities such as battling ropes, kettlebell swings, and sled drags are less commonly discussed but allow for the same goal to be accomplished. Stationary biking can be used to address aerobic deconditioning during the early rehabilitation phase partly due to the minimal stresses placed on the healing graft. Fleming et $\mathrm{al}^{92}$ reported that stationary biking using toe clips placed a mean $1.7 \%$ peak strain on the ACL and did not differ between three power levels (75, 125, and 175 Watts), but peak ACL strain values were highly variable between subjects. This amount of strain during stationary biking is compared to $3.6 \%$ ACL strain observed during squatting and $4.4 \%$ during a 30 Newton-meter (NM) isometric quadriceps contraction at $15^{\circ}$ knee flexion. ${ }^{93,94}$

Various types of aquatic exercise (walking, deep water cycling, swimming) can be effective methods to improve aerobic conditioning early in the rehabilitation process as weight-bearing status can be more closely controlled in a buoyant aquatic environment. With swimming, careful attention needs to be given to the type of kick utilized. ${ }^{95}$ For example, the breaststroke kick, also known as the whipkick, combines hip extension, knee extension, tibial external rotation, and ankle dorsiflexion, which places a relatively high load through the knee. ${ }^{95}$ For this reason, the breaststroke kick should be avoided in athletes until a complete recovery from ACLR has been achieved. Alternatively, the flutter kick, which is used in both the freestyle and backstroke, should be utilized as load is directed primarily to the quadriceps and patellofemoral interface. Underwater treadmill training is another option when clinically appropriate, as similar cardiorespiratory training effects for VO2, RPE, and respiratory exchange ratio were observed during underwater treadmill versus land-based running when performed at maximal exertion levels; however, HR was greater during land-based training comparatively. ${ }^{96}$ Further, a less rigorous training stimulus may occur (VO2) with underwater versus land-based training at submaximal workloads. 96 Some types of underwater treadmills contain cameras to better visualize movement patterns, provide resistance jets, and allow for water depth adjustment via a movable deck. Exercising in water offers a unique environment with the added property of viscosity, where the amount of resistance experienced from viscosity is proportional to the velocity of a movement. ${ }^{97}$ From a multi-physiologic systems approach, one must consider the type of movements performed due to potential implications from water resistance on the musculoskeletal system.

Elliptical running can challenge the cardiopulmonary system to a similar extent to that of running on a treadmill and stair climbing while inducing a greater RPE of the lower extremities, despite similar overall RPEs. ${ }^{98-100}$ However, while elliptical training reduces reaction force during the early stance phase and loading rates during heel strike compared to walking, medial and posterior shear forces placed on the knee as well as peak hip flexor and knee extensor moment were greater; additionally, hip, knee, and ankle flexion angles were greater. 100

Overground treadmill running is a commonly utilized cardiopulmonary training method post-ACLR, however, the vertical ground reaction forces applied to the lower extremity are typically much greater ${ }^{101}$ when compared to walking, ${ }^{102}$ but less than exercises such as unilateral or bilateral drop landing. ${ }^{103}$ However, recent technologies including the use of an unweighted treadmill, such as an AlterG ${ }^{\circledR}$ treadmill (AlterG, Inc., Fremont, CA), may provide a means to reduce loads to the lower extremities during running. ${ }^{104}$ A recent scoping review of 201 studies identified and examined 205 time-based criteria for return to running after ACLR, and found that the median time to allow return to running was 12 weeks, although it is unclear whether this timeframe is safe. ${ }^{105}$ Less than one in five studies reported clinical, strength, or performance-based criteria for decision making regarding return to running after ACLR, which is problematic. Rambaud et al ${ }^{105}$ recommended a combined goal- and time-based criteria to determine return to running after ACLR. Debate exists regarding whether an athlete's kinematics and kinetics are altered when running on a treadmill versus flat ground, however, most research appears to suggest that any alterations are mild, including flight phase time, stride length, cadence, stride frequency, step length, support phase time, foot position, and lumbopelvic-hip kinematics. ${ }^{106,107}$ The mild gait alterations reported with treadmill running suggests that treadmill running is an appropriate step in returning to on-field/court running that may have a carryover effect; however, clinicians will need to determine whether their patient is appropriate for running based on several factors including surgical procedure, clinical status, and activity demands of the athlete. Progression to sport-specific or higher demand cardiopulmonary training is determined on an individual basis, but typically is begun once the athlete has demonstrated the ability to tolerate submaximal loads and built a foundation of cardiopulmonary fitness, not to mention the resolution of necessary impairments in other physiologic systems.

High-intensity interval training (HIIT) has become a popular aerobic conditioning method and involves short bouts $(0.5-8 \mathrm{~min})$ of moderate to high intensity activity, performed in the "severe" intensity domain near the anaerobic threshold, which are alternated with bouts of partial recovery performed at low-intensity or complete rest. This should not be confused with sprint interval training (SIT) which is performed at maximal effort for short bouts $(<30 s)$ followed by complete recovery. ${ }^{108}$ HIIT is often completed via running or biking, however, functional exercises utilizing one's own body weight have also been explored. ${ }^{108,109}$ Previous research has found HIIT to be effective at improving lower extremity power, sprint speed, HR, VO2max, and muscular endurance as effectively or to a greater extent than traditional aerobic training and in a shorter amount of time. ${ }^{109-112}$

Research on HIIT training among healthy soccer and basketball athletes has produced similar findings. Wong et $\mathrm{al}^{113}$ found that vertical jump height, $10-\mathrm{m}$ and $30-\mathrm{m}$ sprint times, laps completed in the Yo-Yo intermittent recovery test, and maximal aerobic speed increased in professional soccer players after completing HIIT training compared to controls. In another study, VO2max, 1,000-m run time, and sprint performance improved after 5 -weeks of HIIT training in adolescent soccer players. ${ }^{114}$ Aschendorf et $\mathrm{al}^{115}$ found that Yo-Yo intermittent recovery test as well as sprint and 
agility test performance without a basketball improved significantly in adolescent female athletes after undergoing a 5-week, basketball-specific HIIT program compared to controls. Specific application of HIIT training with patients post-ACLR has yet to be explored, so clinicians need to determine whether their patient is appropriate for the demands of HIIT training.

\section{CONCLUSION}

Cardiopulmonary system adaptations post-ACLR require careful assessment and intervention planning by the rehabilitation specialist. The integration of the cardiopulmonary system with other physiologic systems supports the aim of attaining efficient, goal-directed human movement after ACLR. Training the cardiopulmonary system after ACLR will in turn impact the health of the integumentary, musculoskeletal, and nervous systems. Selective cardiopulmonary testing and intervention should be integrated along the continuum of rehabilitation. By addressing cardiovascular deficits after ACLR within a multi-physiologic systems approach to resolve movement limitations, clinicians can help to optimize recovery and readiness for sport.

\section{FUNDING}

Dr. Severin receives funding support from the Foundation for Physical Therapy Promotion of Doctoral Studies (PODS) II Scholarship, The APTA Academy of Cardiovascular and Pulmonary Physical Therapy, and The Illinois Physical Therapy Foundation.

\section{ACKNOWLEDGEMENTS}

None.

Submitted: October 01, 2021 CST, Accepted: November 01, 2021 CST 


\section{REFERENCES}

1. American Physical Therapy Association. Guiding Principles to Achieve the Vision. Accessed September 21, 2021. https://www.apta.org/siteassets/pdfs/policie s/guiding-principles-to-achieve-vision.pdf

2. Saladin L, Voight M. Introduction to the movement system as the foundation for physical therapist practice education and research. Int J Sports Phys Ther. 2017;12(6):858-861. doi:10.16603/ijspt2017085 $\underline{8}$

3. Hunter SJ, Norton BJ, Powers CM, Saladin LK, Delitto A. Rothstein roundtable podcast-"Putting all of our eggs in one basket: human movement system." Phys Ther. 2015;95(11):1466-1466. doi:10.2522/ptj.20 15.95.11.1466

4. McClure P, Tevald M, Zarzycki R, et al. The 4-element movement system model to guide physical therapist education, practice, and movement-related research. Phys Ther. 2021;101(3). doi:10.1093/pti/pza b024

5. Davids K, Glazier P, Araújo D, Bartlett R. Movement systems as dynamical systems. Sports Medicine. 2003;33(4):245-260. doi:10.2165/00007256-20033304 0-00001

6. Gerrett N, Griggs K, Redortier B, Voelcker T, Kondo $\mathrm{N}$, Havenith G. Sweat from gland to skin surface: production, transport, and skin absorption. J Appl Physiol. 2018;125(2):459-469. doi:10.1152/japplphysi $\underline{\mathrm{ol} .00872 .2017}$

7. Haff GG, Triplett NT, eds. Essentials of Strength Training and Conditioning: National Strength and Conditioning Association. 4th ed. Human Kinetics; 2016.

8. Song D, Yu DSF. Effects of a moderate-intensity aerobic exercise programme on the cognitive function and quality of life of community-dwelling elderly people with mild cognitive impairment: A randomised controlled trial. Int J Nur Stud. 2019;93:97-105. doi:10.1016/j.ijnurstu.2019.02.019

9. Stern Y, MacKay-Brandt A, Lee S, et al. Effect of aerobic exercise on cognition in younger adults: $A$ randomized clinical trial. Neurology. 2019;92(9):e905-e916. doi:10.1212/wnl.00000000000 $\underline{07003}$
10. Gornitzky AL, Lott A, Yellin JL, Fabricant PD, Lawrence JT, Ganley TJ. Sport-specific yearly risk and incidence of anterior cruciate ligament tears in high school athletes: a systematic review and metaanalysis. Am J Sports Med. 2016;44(10):2716-2723. 으 $\mathrm{i}: 10.1177 / 0363546515617742$

11. Dawson B. Repeated-sprint ability: where are we? Int J Sports Physiol Perform. 2012;7(3):285-289. doi:1 0.1123/ijspp.7.3.285

12. Girard O, Mendez-Villanueva A, Bishop D. Repeated-sprint ability - part I: factors contributing to fatigue. Sports Med. 2011;41(8):673-694. doi:10.21 65/11590550-000000000-00000

13. Almeida AM, Santos Silva PR, Pedrinelli A, Hernandez AJ. Aerobic fitness in professional soccer players after anterior cruciate ligament reconstruction. PLoS One. 2018;13(3):e0194432. doi:1 $\underline{0.1371 / \text { iournal.pone. } 0194432}$

14. Scanlan AT, Dascombe BJ, Reaburn P, Dalbo VJ. The physiological and activity demands experienced by Australian female basketball players during competition. J Sci Med Sport. 2012;15(4):341-347. do i:10.1016/i.jsams.2011.12.008

15. Stojanović E, Stojiljković N, Scanlan AT, Dalbo VI, Berkelmans DM, Milanović Z. The activity demands and physiological responses encountered during basketball match-play: a systematic review. Sports Med. 2018;48(1):111-135. doi:10.1007/s40279-017-07 94-Z

16. Joseph AM, Collins CL, Henke NM, Yard EE, Fields SK, Comstock RD. A multisport epidemiologic comparison of anterior cruciate ligament injuries in high school athletics. J Athl Training. 2013;48(6):810-817. doi:10.4085/1062-6050-48.6.03

17. Dye SF. Therapeutic implications of a tissue homeostasis approach to patellofemoral pain. Sports Med Arthrosc Rev. 2001;9:306-311.

18. Morrison S, Ward P, duManoir GR. Energy system development and load management through the rehabilitation and return to play process. Int J Sports Phys Ther. 2017;12(4):697-710.

19. Logerstedt DS, Scalzitti D, Risberg MA, et al. Knee stability and movement coordination impairments: knee ligament sprain revision 2017. J Orthop Sports Phys Ther. 2017;47(11):A1-A47. doi:10.2519/jospt.201 7.0303 
20. Stølen T, Chamari K, Castagna C, Wisløff U. Physiology of soccer: an update. Sports Med. 2005;35(6):501-536. doi:10.2165/00007256-20053506 $\underline{0-00004}$

21. Zinner C, Sperlich B, Wahl P, Mester J. Classification of selected cardiopulmonary variables of elite athletes of different age, gender, and disciplines during incremental exercise testing. Springerplus. 2015;4:544. doi:10.1186/s40064-015-13 $\underline{41-8}$

22. Bloomfield J, Polman R, O’Donoghue P. Physical demands of different positions in FA Premier League soccer. J Sport Sci Med. 2007;6(1):63-70.

23. Ward PA, Ramsden S, Coutts AJ, Hulton AT, Drust B. Positional differences in running and nonrunning activities during elite American football training. $J$ Strength Cond Res. 2018;32(7):2072-2084. doi:10.151 9/jsc.0000000000002294

24. Wellman AD, Coad SC, Goulet GC, McLellan CP. Quantification of accelerometer derived impacts associated with competitive games in National Collegiate Athletic Association division I college football players. J Strength Cond Res. 2017;31(2):330-338. doi:10.1519/isc.00000000000015 $\underline{06}$

25. Wellman AD, Coad SC, Flynn PJ, Siam TK, McLellan CP. Comparison of preseason and in-season practice and game loads in National Collegiate Athletic Association division I football players. $J$ Strength Cond Res. 2019;33(4):1020-1027. doi:10.151 9/jsc.0000000000002173

26. Petway AJ, Freitas TT, Calleja-González J, Medina Leal D, Alcaraz PE. Training load and match-play demands in basketball based on competition level: A systematic review. PLoS One. 2020;15(3):e0229212. do i:10.1371/journal.pone.0229212

27. Bangsbo J, Iaia FM, Krustrup P. Metabolic response and fatigue in soccer. Int J Sports Physiol Perform. 2007;2(2):111-127. doi:10.1123/ijspp.2.2.111

28. Krustrup P, Mohr M, Steensberg A, Bencke J, Kjaer $\mathrm{M}$, Bangsbo J. Muscle and blood metabolites during a soccer game: implications for sprint performance. Med Sci Sports Exerc. 2006;38(6):1165-1174. doi:10.12 49/01.mss.0000222845.89262.cd

29. Söderlund K, Hultman E. ATP and phosphocreatine changes in single human muscle fibers after intense electrical stimulation. Am J Physiol. 1991;261(6 Pt 1):E737-41. doi:10.1152/ajpend $\underline{0.1991 .261 .6 . E 737}$

30. MacDougall D, Sale D. The Physiology of Training for High Performance. Oxford University Press; 2014.
31. Nalbandian M, Takeda M. Lactate as a signaling molecule that regulates exercise-induced adaptations. Biology (Basel). 2016;5(4). doi:10.3390/bi ology5040038

32. Philp A, Macdonald AL, Watt PW. Lactate--a signal coordinating cell and systemic function. J Exp Biol. 2005;208(Pt 24):4561-4575. doi:10.1242/jeb.019 $\underline{61}$

33. Ali A, Farrally M. Recording soccer players' heart rates during matches. J Sports Sci. 1991;9(2):183-189. $\underline{\text { doi: } 10.1080 / 02640419108729879}$

34. Bangsbo J, Nørregaard L, Thorsø F. Activity profile of competition soccer. Can J Sport Sci. 1991;16(2):110-116

35. Capranica L, Tessitore A, Guidetti L, Figura F. Heart rate and match analysis in pre-pubescent soccer players. J Sports Sci. 2001;19(6):379-384. doi:1 $\underline{0.1080 / 026404101300149339}$

36. Carli G, Bonifazi M, Lodi L, Lupo C, Martelli G, Viti A. Hormonal and metabolic effects following a football match. Int J Sports Med. 1986;7(1):36-38. do i:10.1055/s-2008-1025732

37. Tessitore A, Meeusen R, Tiberi M, Cortis C, Pagano R, Capranica L. Aerobic and anaerobic profiles, heart rate and match analysis in older soccer players. Ergonomics. 2005;48(11-14):1365-1377. doi:10.1080/0 $\underline{0140130500101569}$

38. Berg JM, Tymoczko JL, Stryer L. Glycogen Metabolism. In: Biochemistry. W H Freeman; 2002.

39. Bogdanis GC, Nevill ME, Boobis LH, Lakomy HK. Contribution of phosphocreatine and aerobic metabolism to energy supply during repeated sprint exercise. J Appl Physiol (1985). 1996;80(3):876-884. do i:10.1152/jappl.1996.80.3.876

40. Mujika I, Padilla S. Detraining: loss of traininginduced physiological and performance adaptations. Part I: short term insufficient training stimulus. Sports Med. 2000;30(2):79-87. doi:10.2165/0000725 6-200030020-00002

41. Mujika I, Padilla S. Detraining: loss of traininginduced physiological and performance adaptations. Part II: Long term insufficient training stimulus. Sports Med. 2000;30(3):145-154. doi:10.2165/0000725 6-200030030-00001

42. Girardi M, Casolo A, Nuccio S, Gattoni C, Capelli C. Detraining effects prevention: a new rising challenge for athletes. Front Physiol. 2020;11(1234). d oi:10.3389/fphys.2020.588784 
43. Bishop D, Spencer M. Determinants of repeatedsprint ability in well-trained team-sport athletes and endurance-trained athletes. J Sports Med Phys Fitness. 2004;44(1):1-7.

44. Steding-Ehrenborg K, Hedén B, Herbertsson P, Arheden H. A longitudinal study on cardiac effects of deconditioning and physical reconditioning using the anterior cruciate ligament injury as a model. Clin Physiol Funct Imaging. 2013;33(6):423-430. doi:10.111 $\underline{1 / \mathrm{cpf} .12048}$

45. Burnsed-Torres ML, Wichmann TK, Clayton ZS, Hahn ME. Comparison of the Gauntlet Test with standard laboratory measures of aerobic fitness. $J$ Strength Cond Res. Published online 2019. doi:10.151 9/ISC.0000000000003452

46. Ness BM, Zimney K, Schweinle WE. Analysis of Gauntlet Test performance and injury risk in intercollegiate division I female soccer (football) players: a retrospective study. J Sport Rehabil. 2017;26:536-543. doi:10.1123/jsr.2016-0097

47. Heidt RS Jr, Sweeterman LM, Carlonas RL, Traub JA, Tekulve FX. Avoidance of soccer injuries with preseason conditioning. Am J Sports Med. 2000;28(5):659-662. doi:10.1177/03635465000280050 $\underline{601}$

48. Pedlar CR, Brown MG, Shave RE, et al. Cardiovascular response to prescribed detraining among recreational athletes. J Appl Physiol. 2018;124(4):813-820. doi:10.1152/japplphysiol.0091 1.2017

49. Cullinane EM, Sady SP, Vadeboncoeur L, Burke M, Thompson PD. Cardiac size and VO2max do not decrease after short-term exercise cessation. Med Sci Sports Exerc. 1986;18(4):420-424.

50. Coyle EF, Hemmert MK, Coggan AR. Effects of detraining on cardiovascular responses to exercise: role of blood volume. J Appl Physiol. 1986;60(1):95-99. doi:10.1152/jappl.1986.60.1.95

51. Hughson RL, Shoemaker JK. Autonomic responses to exercise: deconditioning/inactivity. Auton Neurosci. 2015;188:32-35. doi:10.1016/j.autneu.2014.10.012

52. Beaver WL, Wasserman K, Whipp BJ. A new method for detecting anaerobic threshold by gas exchange. J Appl Physiol. 1986;60(6):2020-2027. doi:1 0.1152/jappl.1986.60.6.2020

53. Santos-Silva PR, Fonseca AJ, Castro AW, Greve JM, Hernandez AJ. Reproducibility of maximum aerobic power (VO2max) among soccer players using a modified heck protocol. Clinics (Sao Paulo). 2007;62(4):391-396. doi:10.1590/s1807-59322007000 $\underline{400004}$
54. Olivier N, Legrand R, Rogez J, Berthoin S, Weissland T. Effects of knee surgery on cardiac function in soccer players. Am J Phys Med Rehabil. 2007;86(1):45-49. doi:10.1097/phm.0b013e31802b833 a

55. Neufer PD. The effect of detraining and reduced training on the physiological adaptations to aerobic exercise training. Sports Med. 1989;8(5):302-320. do i:10.2165/00007256-198908050-00004

56. Stebbings GK, Morse CI, McMahon GE, Onambele GL. Resting arterial diameter and blood flow changes with resistance training and detraining in healthy young individuals. J Athl Train. 2013;48(2):209-219. d oi:10.4085/1062-6050-48.1.17

57. Palmieri-Smith RM, Lepley LK. Quadriceps strength asymmetry after anterior cruciate ligament reconstruction alters knee joint biomechanics and functional performance at time of return to activity. Am J Sports Med. 2015;43(7):1662-1669. doi:10.1177/0 $\underline{363546515578252}$

58. Zwolski C, Schmitt LC, Quatman-Yates C, Thomas S, Hewett TE, Paterno MV. The influence of quadriceps strength asymmetry on patient-reported function at time of return to sport after anterior cruciate ligament reconstruction. Am J Sports Med. 2015;43(9):2242-2249. doi:10.1177/036354651559125 $\underline{8}$

59. Ishida K, Katayama K, Akima H, et al. Effects of deconditioning on the initial ventilatory and circulatory responses at the onset of exercise in man. Adv Exp Med Biol. 2010;669:319-322. doi:10.1007/97 8-1-4419-5692-7 65

60. Alvero-Cruz JR, Ronconi M, Garcia Romero J, Naranjo Orellana J. Effects of detraining on breathing pattern and ventilatory efficiency in young soccer players. J Sports Med Phys Fitness. 2019;59(1):71-75. $\underline{\mathrm{d}}$ oi:10.23736/s0022-4707.17.07619-8

61. Impellizzeri FM, Marcora SM, Coutts AJ. Internal and external training load: 15 years on. Int J Sports Physiol Perform. 2019;14(2):270-273. doi:10.1123/ijsp p.2018-0935

62. Kaminsky LA, Arena R, Myers J. Reference standards for cardiorespiratory fitness measured with cardiopulmonary exercise festing: data from the fitness registry and the importance of exercise national database. Mayo Clin Proc. 2015;90(11):1515-1523. doi:10.1016/j.mayocp.2015.0 $\underline{7.026}$ 
63. Anderson L, Orme P, Naughton RJ, et al. Energy intake and expenditure of professional soccer players of the English Premier League: evidence of carbohydrate periodization. Int J Sport Nutr Exerc Metab. 2017;27(3):228-238. doi:10.1123/ijsnem.201 6-0259

64. Taylor M, Nagle EF, Goss FL, Rubinstein EN, Simonson A. Evaluating energy expenditure estimated by wearable technology during variable intensity activity on female collegiate athletes. Int $J$ Exerc Sci. 2018;11(7):598-608.

65. Kenney WL, Wilmore JH, Costill DL. Physiology of Sport and Exercise. 7th ed. Human Kinetics Publishers; 2019.

66. Shephard RJ, Bailey DA, Mirwald RL. Development of the Canadian Home Fitness Test. CMAJ. 1976;114(8):675-679.

67. Wang R, Blackburn G, Desai M, et al. Accuracy of wrist-worn heart rate monitors. JAMA Cardiology. 2017;2(1):104-106. doi:10.1001/jamacardio.2016.3340

68. Gillinov S, Etiwy M, Wang R, et al. Variable accuracy of wearable heart rate monitors during aerobic exercise. Med Sci Sports Exerc. 2017;49(8):1697-1703. doi:10.1249/mss.00000000000 $\underline{01284}$

69. Stahl SE, An HS, Dinkel DM, Noble JM, Lee JM. How accurate are the wrist-based heart rate monitors during walking and running activities? Are they accurate enough? BMJ Open Sport \&amp; Exercise Medicine. 2016;2(1):e000106. doi:10.1136/bmjsem-20 15-000106

70. Terbizan DJ, Dolezal BA, Albano C. Validity of seven commercially available heart rate monitors. Meas Phys Educ Exerc Sci. 2002;6(4):243-247. doi:10.1 207/S15327841MPEE0604 3

71. Scherr J, Wolfarth B, Christle JW, Pressler A, Wagenpfeil S, Halle M. Associations between Borg's rating of perceived exertion and physiological measures of exercise intensity. Eur J Appl Physiol. 2013;113(1):147-155. doi:10.1007/s00421-012-2421-x

72. Borg GA. Psychophysical bases of perceived exertion. Med Sci Sports Exerc. 1982;14(5):377-381.

73. Banerjee D, Kamuren J, Baird GL, et al. The Modified Borg Dyspnea Scale does not predict hospitalization in pulmonary arterial hypertension. Pulm Circ. 2017;7(2):384-390. doi:10.1177/204589321 $\underline{7695568}$
74. Borg E, Borg G, Larsson K, Letzter M, Sundblad BM. An index for breathlessness and leg fatigue. Scand J Med Sci Sports. 2010;20(4):644-650. doi:10.11 11/j.1600-0838.2009.00985.x

75. Balady GJ, Arena R, Sietsema K, et al. Clinician's Guide to cardiopulmonary exercise testing in adults: a scientific statement from the American Heart Association. Circulation. 2010;122(2):191-225. doi:1 $\underline{0.1161 / C I R .0 b 013 e 3181 \mathrm{e} 52 \mathrm{e} 69}$

76. Fletcher GF, Ades PA, Kligfield P, et al. Exercise standards for testing and training: a scientific statement from the American Heart Association. Circulation. 2013;128(8):873-934. doi:10.1161/CIR.0b $\underline{013 \mathrm{e} 31829 \mathrm{~b} 5 \mathrm{~b} 44}$

77. Dreger RW, Quinney HA. Development of a hockey-specific, skate-treadmill VO2 max protocol. Can J Appl Physiol. 1999;24(6):559-569. doi:10.1139/h 99-037

78. Edwards AM, Clark N, Macfadyen AM. Lactate and ventilatory thresholds reflect the training status of professional soccer players where maximum aerobic power is unchanged. J Sports Sci Med. 2003;2(1):23-29.

79. Watson A, Brindle J, Brickson S, Allee T, Sanfilippo J. Preseason aerobic capacity is an independent predictor of in-season injury in collegiate soccer players. Clin J Sport Med. 2017;27(3):302-307. doi:10.1097/jsm.00000000000003 $\underline{31}$

80. Clark NA, Edwards AM, Morton RH, Butterly RJ. Season-to-season variations of physiological fitness within a squad of professional male soccer players. J Sports Sci Med. 2008;7(1):157-165.

81. Bellenger CR, Fuller JT, Nelson MJ, Hartland M, Buckley JD, Debenedictis TA. Predicting maximal aerobic speed through set distance time-trials. Eur J Appl Physiol. 2015;115(12):2593-2598. doi:10.1007/s0 0421-015-3233-6

82. Berthoin S, Gerbeaux M, Turpin E, Guerrin F, Lensel-Corbeil G, Vandendorpe F. Comparison of two field tests to estimate maximum aerobic speed. $J$ Sports Sci. 1994;12(4):355-362. doi:10.1080/02640419 408732181

83. Bediz CS, Gökbel H, Kara M, Uçok K, Cikrikçi E, Ergene N. Comparison of the aerobic contributions to Wingate anaerobic tests performed with two different loads. J Sports Med Phys Fitness. 1998;38(1):30-34. 
84. Jaafar H, Rouis M, Coudrat L, Attiogbé E, Vandewalle H, Driss T. Effects of load on wingate test performances and reliability. J Strength Cond Res. 2014;28(12):3462-3468. doi:10.1519/jsc.00000000000 $\underline{00575}$

85. Bar-Or O. The Wingate anaerobic test. An update on methodology, reliability and validity. Sports Med. 1987;4(6):381-394. doi:10.2165/00007256-19870406 $\underline{0-00001}$

86. Nikolaidis PT, Matos B, Clemente FM, et al. Normative data of the Wingate anaerobic test in 1 year age groups of male soccer players. Front Physiol. 2018;9(1619). doi:10.3389/fphys.2018.01619

87. Baker UC, Heath EM, Smith DR, Oden GL. Development of Wingate Anaerobic Test norms for highly-trained women. J Exerc Physiol Online. 2011;14:68+.

88. Schmitz B, Pfeifer C, Kreitz K, Borowski M, Faldum A, Brand SM. The Yo-Yo intermittent tests: a systematic review and structured compendium of test results. Front Physiol. 2018;9:870. doi:10.3389/fphys.2 $\underline{018.00870}$

89. Martinez-Lagunas V, Hartmann U. Validity of the Yo-Yo Intermittent Recovery Test Level 1 for direct measurement or indirect estimation of maximal oxygen uptake in female soccer players. Int J Sports Physiol Perform. 2014;9(5):825-831. doi:10.1123/ijsp p.2013-0313

90. Buckthorpe M, Tamisari A, Villa FD. A ten taskbased progression in rehabilitation after ACL reconstruction: from post-surgery to return to play a clinical commentary. Int J Sports Phys Ther. 2020;15(4):611-623.

91. Della Villa S, Boldrini L, Ricci M, et al. Clinical outcomes and return-to-sports participation of 50 soccer players after anterior cruciate ligament reconstruction through a sport-specific rehabilitation protocol. Sports Health. 2012;4(1):17-24. doi:10.1177/ $\underline{1941738111417564}$

92. Fleming BC, Beynnon BD, Renstrom PA, Peura GD, Nichols CE, Johnson RJ. The strain behavior of the anterior cruciate ligament during bicycling. An in vivo study. Am J Sports Med. 1998;26(1):109-118. do i:10.1177/03635465980260010301

93. Beynnon BD, Fleming BC. Anterior cruciate ligament strain in-vivo: a review of previous work. $J$ Biomech. 1998;31(6):519-525. doi:10.1016/s0021-929 0(98)00044-x
94. Beynnon BD, Johnson RJ, Fleming BC, Stankewich CJ, Renström PA, Nichols CE. The strain behavior of the anterior cruciate ligament during squatting and active flexion-extension. A comparison of an open and a closed kinetic chain exercise. Am J Sports Med. 1997;25(6):823-829. doi:10.1177/03635465970250061 $\underline{6}$

95. Rodeo SA. Knee pain in competitive swimming. Clin Sports Med. 1999;18(2):379-387, viii. doi:10.1016/ s0278-5919(05)70152-6

96. Schaal CM, Collins LH, Ashley C. Cardiorespiratory responses to underwater treadmill running versus land-based treadmill running. Int J Aquatic Res Educ. 2012;6:6.

97. Bukowski EL. Aquatic exercise. In: Kisner C, Colby LA, Borstad J, eds. Therapeutic Exercise: Foundations and Techniques. 7th ed. F.A. Davis; 2018:295-319.

98. Batté AL, Darling J, Evans J, Lance LM, Olson EI, Pincivero DM. Physiologic response to a prescribed rating of perceived exertion on an elliptical fitness cross-trainer. J Sports Med Phys Fitness. 2003;43(3):300-305

99. Egaña M, Donne B. Physiological changes following a 12 week gym based stair-climbing, elliptical trainer and treadmill running program in females. J Sports Med Phys Fitness. 2004;44(2):141-146.

100. Lu TW, Chien HL, Chen HL. Joint loading in the lower extremities during elliptical exercise. Med Sci Sports Exerc. 2007;39(9):1651-1658. doi:10.1249/ms s.0b013e3180dc9970

101. Bowersock CD, Willy RW, DeVita P, Willson JD. Reduced step length reduces knee joint contact forces during running following anterior cruciate ligament reconstruction but does not alter inter-limb asymmetry. Clin Biomech. 2017;43:79-85. doi:10.101 6/i.clinbiomech.2017.02.004

102. Pietrosimone B, Seeley MK, Johnston C, Pfeiffer SI, Spang JT, Blackburn JT. Walking ground reaction force post-ACL reconstruction: analysis of time and symptoms. Med Sci Sports Exerc. 2019;51(2):246-254. doi:10.1249/MSS.0000000000001776

103. Zadpoor AA, Nikooyan AA. The effects of lowerextremity muscle fatigue on the vertical ground reaction force: a meta-analysis. Proc Inst Mech Eng H. 2012;226(8):579-588. doi:10.1177/0954411912447021

104. Grabowski AM, Kram R. Effects of velocity and weight support on ground reaction forces and metabolic power during running. I Appl Biomech. 2008;24(3):288-297. doi:10.1123/jab.24.3.288 
105. Rambaud AJM, Ardern CL, Thoreux P, Regnaux JP, Edouard P. Criteria for return to running after anterior cruciate ligament reconstruction: a scoping review. Br J Sports Med. 2018;52(22):1437-1444. doi:1 0.1136/bjsports-2017-098602

106. Nigg BM, De Boer RW, Fisher V. A kinematic comparison of overground and treadmill running. Med Sci Sports Exerc. 1995;27(1):98-105.

107. Riley PO, Dicharry J, Franz J, Della Croce U, Wilder RP, Kerrigan DC. A kinematics and kinetic comparison of overground and treadmill running. Med Sci Sports Exerc. 2008;40(6):1093-1100. doi:10.12 49/MSS.0b013e3181677530

108. Laursen PB, Shing CM, Peake JM, Coombes JS, Jenkins DG. Interval training program optimization in highly trained endurance cyclists. Med Sci Sports Exerc. 2002;34(11):1801-1807. doi:10.1097/0000576 8-200211000-00017

109. Menz V, Marterer N, Amin SB, Faulhaber M, Hansen $A B$, Lawley JS. Functional vs. running lowvolume high-intensity interval training: effects on VO2max and muscular endurance. J Sports Sci Med. 2019;18(3):497-504.

110. García-Pinillos F, Soto-Hermoso VM, LatorreRomán PA. How does high-intensity intermittent training affect recreational endurance runners? Acute and chronic adaptations: a systematic review. J Sport Health Sci. 2017;6(1):54-67. doi:10.1016/j.jshs.2016.0 $\underline{8.010}$
111. Esfarjani F, Laursen PB. Manipulating highintensity interval training: effects on VO2max, the lactate threshold and $3000 \mathrm{~m}$ running performance in moderately trained males. J Sci Med Sport. 2007;10(1):27-35. doi:10.1016/j.jsams.2006.05.014

112. Gibala MJ, Little JP, Macdonald MJ, Hawley JA. Physiological adaptations to low-volume, highintensity interval training in health and disease. $J$ Physiol. 2012;590(5):1077-1084. doi:10.1113/jphysio $\underline{1.2011 .224725}$

113. Wong PL, Chaouachi A, Chamari K, Dellal A, Wisloff U. Effect of preseason concurrent muscular strength and high-intensity interval training in professional soccer players. J Strength Cond Res. 2010;24(3):653-660. doi:10.1519//SC.0b013e3181aa36 a2

114. Sperlich B, De Marées M, Koehler K, Linville J, Holmberg HC, Mester J. Effects of 5 weeks of highintensity interval training vs. volume training in 14-year-old soccer players. J Strength Cond Res. 2011;25(5):1271-1278. doi:10.1519/ISC.0b013e3181d $\underline{67 c 38}$

115. Aschendorf PF, Zinner C, Delextrat A, Engelmeyer E, Mester J. Effects of basketball-specific high-intensity interval training on aerobic performance and physical capacities in youth female basketball players. Phys Sportsmed. 2019;47(1):65-70. doi:10.1080/00913847.2018.1520054 